\title{
Leading the Fight Against the Pandemic: Does Gender 'Really' Matter?
}

by Supriya Garikipati and Uma Kambhampati

Discussion Paper No. 2020-13

Department of Economics University of Reading Whiteknights

Reading

RG6 6AA

United Kingdom

www.reading.ac.uk 


\title{
Leading the Fight Against the Pandemic: Does Gender 'Really’ Matter?
}

\author{
Supriya Garikipati† and Uma Kambhampati ${ }^{1 *}$ \\ †University of Liverpool, *University of Reading,
}

\begin{abstract}
Since the start of the ongoing coronavirus pandemic, the relationship between national female leaders and their effectiveness in handling the COVID-crisis has received a lot of media attention. In this paper we scrutinise this association more systematically. We ask if there is a significant and systematic difference by gender of the national leader in the number of COVIDcases and deaths in the first quarter of the pandemic. We also examine differences in policy responses by male vs. female leaders as plausible explanations for the differences in outcomes. Using a constructed dataset for 194 countries, a variety of socio-demographic variables are used to match nearest neighbours. Our findings show that COVID-outcomes are systematically better in countries led by women and, to some extent, this may be explained by the proactive and coordinated policy responses adopted by them. We use insights from behavioural studies and leadership literature to speculate on the sources of these differences, as well as on their implications. Our hope is that this article will serve as a starting point to illuminate the discussion on the influence of national leaders in explaining the differences in country COVIDoutcomes.
\end{abstract}

Key words: COVID-19, Pandemic, National Leadership, Women Leaders, Risk Aversion.

\footnotetext{
${ }^{1}$ We are grateful for research support provided by Antara Mandal. Any errors remain the responsibility of the authors.
} 


\section{Introduction}

National responses to the COVID-19 pandemic and their outcomes have been avidly compared across the world. Given the importance of leadership in times of crisis, national leaders have also been in the spotlight. Have leaders been slow in recognising the risks? Have they engaged with the science? Have they weighted the economic costs more heavily than the loss of lives? In this context, much has been written about the performance of women leaders (e.g., Taub, 2020; Friedman, 2020; Wittenberg-Cox, 2020). Much of the media analysis however, has been about two high-profile female leaders (Angela Merkel and Jacinda Ardern) who have steered their countries through the initial few weeks with less loss of life than their immediate comparators in Europe.

In this paper, we consider the question of national leader's gender and COVID-outcomes more systematically and discuss some of the plausible reasons for our findings. Using a 194-country dataset, specifically constructed for this purpose, we analyse two main questions. First, are there any significant and systematic differences in the COVID-outcomes of male and female led-countries in the first quarter of the pandemic? Second, can we point to any differences in policy measures adopted by male and female leaders that might explain the differences in outcomes? In particular, we consider the timing of lockdown in these countries.

The paper relates to various branches of literature that examine gender-differences in behaviour. Closely related is the literature on gender-differences in attitudes to risk and uncertainty. Studies in this area are largely focused on analysing decision-making in experimental settings. There is strong evidence within this literature that women, even those in leadership roles, appear to be more risk-averse than men (e.g., Croson and Gneezy, 2009; Charness and Gneezy, 2012). While this headline result is far from canonical (Nelson, 2015), especially given the role that cultural and contextual modulators play (see Finucane et al., 2000; Schubert, 1999), there is a high level of consistency in the frequency with which it surfaces. For example, Charness and Gneezy (2012) assemble 15 different studies that report findings from one underlying investment game, carried out in different countries, with different instructions, durations, payments and subject pools. They find a very consistent result that men invest more, and thus appear to be more risk taking than women. Indeed, in the current crisis, several incidents of risky behaviour by male leaders have been reported in the press. Particularly noteworthy among these are Brazil's Jair Bolsonaro’s dismissal of COVID-19 as “a little flu or a bit of a cold”, while attending an anti-lockdown protest in April and Britain’s 
Boris Johnson's statement, “I was at a hospital where there were a few coronavirus patients and I shook hands with everybody" (as reported in Lewis, 2020). Given the consistent result on women's relative aversion to risk and anecdotal reports of risky behaviour by male leaders, it is tempting to draw simplistic conclusions. A reliable conclusion on the issue however requires more systematic investigation.

The second strand of literature that our paper relates to is that on the role of leaders in national outcomes. The question of national leadership has given rise to a voluminous literature that lends texture to two conceptually extreme opinions: the idea that powerful leaders are simply a social myth, created to satisfy our psychological needs (Gemmill and Oakley, 1992) vs. the view that, a handful of influential leaders could be seen as determining the course of history (Keegan, 2003). In their seminar work, Jones and Olken (2005) use death of a leader as an exogenous variation in leadership and find that individual leaders can play a crucial role in shaping the growth of nations. Building on this, Besley, Montalvo and Reynal-Querol (2011) find that more competent leaders (specifically in terms of education and skills) result in better national outcomes. The skill and attainment of the leader is also found to matter in other general settings, like that of organisational performance (Goodall, Kahn and Oswald, 2011).

The performance of female leaders in the COVID pandemic offers a unique global experiment in national crisis management where various issues, including that of effectiveness of leadership, can be examined across countries. There are very few studies about the impact of leader's gender in a national crisis, partly at least, because there are so few female leaders. In our sample of 194 countries, we have just 19 (<10\%) female leaders. This lack of female leadership has given way to 'single-sex' conjectures that support the 'Great Men' view of history, within which, events are determined by the instrumental and causal influence of a small number of men. For example, Keegan (2003) writes that the political history of the last century can be found in the biographies of six men: Lenin, Stalin, Hitler, Mao, Roosevelt, and Churchill. However, if a leader's attributes have explanatory power, as much of the literature concludes, then it is a natural next step to ask whether the gender of the national leader, that may represent inherent proclivity for certain type of policy making, exerts an influence on outcomes, especially in the case of an emergency like the pandemic.

A note of caution before we begin. The pandemic is still in its early stages and therefore our analysis relates only to the initial responses of national leaders and initial outcomes of the 
pandemic. Given the fast-evolving situation, much will change over the next few months. Despite this, the first quarter reactions and outcomes are revealing because they capture immediate policy responses during an emergency. They therefore highlight the significance of early and effective management in a crisis.

The rest of the paper is arranged as follows. The next section discusses construction of the dataset and methodology. Section 3 presents the results. Section 4 uses insights from risk and leadership literature to speculate on the sources of these differences. Section 5 concludes.

\section{Data and Methodology}

Data construction

This paper uses a dataset specially collected by the authors for the purpose of this enquiry. We gathered information on total deaths and total cases due to COVID up to May $19^{\text {th }}$ from the Worldometer site. We merged this data with a range of socio-demographic and economic data obtained from the World Development Indicators and UNDP's Human Development Indicators for 194 countries. We collated data on current female leaders from various websites. If countries have more than one head of state, we made a distinction between the executive head (de facto head) and the titular head (de jure or nominal head) based on the characteristics of the political system. We followed the general rule that: in parliamentary regimes, the prime minister is the executive leader while in presidential systems, it is the president, and in communist states, the chairman of the party is the executive head of state. We use this dataset to analyse first, if there is a systematic difference by gender of the national leader in the total number of deaths and cases experienced due to COVID-19. We also use it to consider the national policy responses to the pandemic, particularly the timing of lockdown.

The first step of our analysis centres around two outcome variables - the total number of COVID cases and total deaths. There are several problems with the quality of data currently available. In particular, the number of cases depends on the amount of testing that a country has been able to undertake. With the shortage of test kits, most countries have undertaken less than optimal testing. Over time, the amount of testing being undertaken is increasing as more testing capacity is being made available. To the extent that tests are being reserved for those who are symptomatic, data on deaths is likely to be more reliable though there are concerns about its comparability across countries. In some countries, if a COVID-positive individual 
dies, the death is registered as a COVID-death, irrespective of any other previous illness (like tuberculosis, cancer). But this is not standard or mandatory, so practice varies across countries. Our analysis is based on the best and most comprehensive data available but it is subject to these limitations. As time progresses better COVID data will become available and this analysis can be updated.

One other issue that needs to be highlighted is the fact that we are still very much at the start of the pandemic. There is the expectation that the pandemic will last for another 12-18 months, until we find a vaccine or develop herd immunity (Gallagher, 2020). Our analysis therefore is only about the immediate reaction to the first wave. Outcomes by the end of the pandemic will depend on a range of other issues including the impact of other institutions, the cultural norms prevalent in countries and the impact of the lockdown on the economy, health and well-being of individuals.

\section{Methodology}

As mentioned above, any investigation involving female leaders suffers from the problem of small sample size, with only 19 out of 194 countries being led by women in our data. In addition, countries that select female leaders may have specific characteristics which enable them to respond to such crises better. They may be richer, less populous or have better gender relations. Countries that select female leaders may also be more 'modern' and 'equitable' and therefore perform better during crises. Thus, OLS estimation could suffer from two problems

- that of a small number of female-led countries and the potential problem of selection. To correct for these two problems, we use the nearest neighbour matching method wherein we compare a unit in the treated group (female-led countries) with a unit in the control group that is as similar to it as possible along a range of covariates. Matching is a quasi-experimental technique that provides a more reliable way of comparing two groups when sample sizes are heavily imbalanced and where they may be selection issues (see Durrant, 2009; Stuart, 2010).

The nearest neighbour matching method pairs each female-led country in our sample with its closest comparator and estimates the effect of being female-led on the dependent variables (COVID-cases and deaths). The initial matching is done based on four socio-demographic and economic variables that have been seen as important in the transmission of COVID-19 - GDP per capita (current USD), Population, Population in Urban agglomerations and Population over 65 Years. We use these variables to match for a range of reasons. First, we include GDP per 
capita as both the impact of COVID-19 and the ability to respond to it are likely to be influenced by how rich or poor a country is (Barnett-Howell and Mobarak, 2020). Second, the population variable helps us to control for differences in population size and the statistical impact it may have on numbers and spread. Third, we include Population in urban agglomerations as a matching variable because it has been remarked that COVID-19 spreads faster in densely populated regions (Zhang, et.al., 2020). Finally, we include population over 65 because one of the few clear patterns of COVID-19 deaths across the world is that it is especially fatal amongst older individuals, with the death rates climbing steeply for the over 60s (Nikolich-Zugich, et.al., 2020; Zhang, et.al., 2020).

We follow this core analysis by testing for robustness across the sample as well as across matching variables. In our estimation, we consider not only the nearest neighbour but also two nearest, three nearest and five nearest neighbours to consider how robust the effect is. We also extend our matching variables to include three other characteristics - Annual Health Expenditure per capita, Number of Tourists entering the country and Gender Equality. Each of these variables allows us to control for a range of differences that could be significant in determining the outcome variables.

We may expect that countries that have a better equipped health system are likely to perform better in the ongoing crisis. We hence extend our matching model by including the annual expenditure on health in each country (current USD). We match by openness to tourism because the more open a country is to international travel, the harder it will be to control the initial importation of the pandemic. It has been mooted that countries that have more gender equitable institutions might well be those that elect women leaders and that, it is their gender equality more generally rather than their women leaders that have facilitated their differentially better outcomes (e.g., Champoux-Paillé and Croteau, 2020). This may not only mean that women find gaining power easier in these countries, but that women in power may also enjoy greater trust and support from a political and social context that perpetuates the acceptance of female leaders, and may find it easier to champion cautious policies, if they choose to do so. Indeed, the COVID-19 experience of a group of Scandinavian countries may well fall in this category. Matching by the Gender Inequality Index (GII) therefore allows us to control for these differences between the women-led countries and their comparators and to identify the impact of a country being female-led more precisely. 


\section{Results}

\section{COVID-cases and deaths by gender of leader}

Table 1 below presents summary statistics for the matching covariates and dependent variables by gender of the country's leaders. Although these are raw statistics and not useful to draw inferences, it is clear that female-led countries have fared better in terms of absolute number of COVID-cases and deaths, with male-led countries having nearly double the number of deaths as female-led ones.

Table 1: Summary statistics for matching covariates and dependent variables by gender of leaders

\begin{tabular}{|c|c|c|c|c|c|c|c|c|}
\hline \multirow[b]{2}{*}{ Study variable } & \multicolumn{4}{|c|}{ Female-led $(N=19)$} & \multicolumn{4}{|c|}{ Male-led ( $N=172$, unless stated otherwise) } \\
\hline & Mean & SD & Min & Max & Mean & SD & Min & Max \\
\hline \multicolumn{9}{|l|}{ First stage matching covariate } \\
\hline GDP pc (current USD) & 34,902 & 29,810 & 0 & 82,797 & 12,960 & 22,321 & 0 & 185,741 \\
\hline Population & $2.017 \mathrm{e}+07$ & $4.084 \mathrm{e}+07$ & 38,717 & $1.647 \mathrm{e}+08$ & $4.233 \mathrm{e}+07$ & $1.564 \mathrm{e}+08$ & 30,231 & $1.439 \mathrm{e}+09$ \\
\hline Pop in urban agglomerations & 24.56 & 29.16 & 0 & 100 & 15.04 & 16.89 & 0 & 72.25 \\
\hline Population 65 years and over & 13.52 & 6.764 & 0 & 21.72 & 7.826 & 6.331 & 0 & 27.58 \\
\hline \multicolumn{9}{|l|}{ Extended matching covariate } \\
\hline Avg annual pc health expenditure & 2,150 & 2,469 & 0 & 7,375 & 659.9 & 1,207 & 0 & 7,456 \\
\hline Number of international tourists & $7.554 \mathrm{e}+06$ & $1.042 \mathrm{e}+07$ & 0 & $3.888 \mathrm{e}+07$ & $7.212 \mathrm{e}+06$ & $1.473 \mathrm{e}+07$ & 0 & $8.932 \mathrm{e}+07$ \\
\hline $\begin{array}{l}\text { Gender Inequality Index } 2017 \\
\text { Dependent variable }\end{array}$ & 0.189 & 0.179 & 0.0390 & 0.542 & $0.365(N=139)$ & 0.185 & 0.0440 & 0.834 \\
\hline Total COVID-cases & 19,064 & 41,040 & 12 & 177,289 & $26,468(N=171)$ & 127,125 & 8 & $1.550 \mathrm{e}+06$ \\
\hline Total COVID-deaths & 1,107 & 2,681 & 1 & 9,080 & $2,021(N=148)$ & 9,104 & 1 & 91,981 \\
\hline
\end{tabular}

Source: Dataset constructed by authors from various sources.

Table 2: OLS results for COVID-cases and deaths

\begin{tabular}{lcc}
\hline Covariates & Total cases & Total deaths \\
\hline Female-led & $-42,237.982$ & $-3,553.061^{*}$ \\
& $(29,256.013)$ & $(2,085.571)$ \\
GDP pc & $0.780^{* *}$ & $0.060^{* *}$ \\
& $(0.388)$ & $(0.029)$ \\
Population & $0.000^{* * *}$ & $0.000^{* *}$ \\
& $(0.000)$ & $(0.000)$ \\
Population in urban agglomerations & $870.373^{*}$ & 46.571 \\
Population 65 years and over & $(463.317)$ & $(34.205)$ \\
& $2,383.713^{*}$ & $252.498^{* *}$ \\
& $(1,413.149)$ & $(103.215)$ \\
Constant & $-23,216.544$ & $-2,181.782^{*}$ \\
\hline Observations & $(14,475.292)$ & $(1,150.559)$ \\
R-squared & 190 & 167 \\
\hline
\end{tabular}

Note. Standard errors in parenthesis

$* * * \mathrm{p}<0.01, * * \mathrm{p}<0.05, * \mathrm{p}<0.1$ 


\section{- COVID-outcomes (first step matching)}

To get around the small sample size problem while also controlling for various characteristics, we use the nearest neighbour matching method. This method matches each of the 19 femaleled countries in our sample with their nearest neighbour using four matching characteristics GDP per capita, population, population in urban agglomerations and size of elderly dependants. To test the robustness of our results, we also match with two, three and five nearest neighbours. Table 3a presents the results for matched estimations for both total COVID-cases and deaths. Our matched estimations show a definite and consistent pattern, confirming that the number of deaths is lower in women-led countries than in countries led by men. This is also true of the number of cases, though here the significance of the treatment variable decreases as we increase the number of matches. This suggests that controlling for GDP per capita, population, size of urban population and of elderly, female-led countries perform significantly better than maleled countries.

Table 3a: Comparing COVID-outcomes in female-led countries with nearest neighbours (first step matching)

\begin{tabular}{lccc}
\hline Dependent variable & Nearest neighbour & Two nearest neighbours & Three nearest neighbours \\
\hline COVID-cases $(N=190)$ & $-20,578.153^{* *}$ & $-18,976.005^{*}$ & $-15,836.658$ \\
& $(9,546.513)$ & $(9,748.711)$ & $(9,769.106)$ \\
COVID-deaths $(N=167)$ & $-1,673.826^{* *}$ & $-1,686.569 * *$ & $-1,634.265^{* *}$ \\
& $(739.533)$ & $(705.023)$ & $(713.384)$ \\
\hline
\end{tabular}

Note. Standard errors in parenthesis. Results for five nearest neighbours are similar.

$* * \mathrm{p}<0.05, * \mathrm{p}<0.1$

\section{- COVID-outcomes (extended matching)}

As mentioned earlier, to test the robustness of our results, we extend the matching to include three other variables that are likely to have an impact on COVID-outcomes are: the condition of the country's health care systems which will impact on its ability to fight the pandemic; openness to tourism which has been professed to affect the rate and speed of transmission, especially in the first quarter before the lockdown; and finally, more liberal and equitable sociocultural norms which may support policy making and compliance in times of crisis.

Table $3 \mathrm{~b}$ presents the results for these extensions to the results. As before, we estimate the extension matching models for the nearest neighbours, for two, three and five nearest neighbours. Our results remain robust across these estimations, hence in the interest of space we present results only for the nearest neighbour. Overall, we find that both cases and deaths continue to be lower for female-led countries when we match using the three extension variables. 
With respect to health expenditure, conceptually speaking, we might expect this variable to both influence the number of deaths as well as the readiness with which a country is willing to shut down. In particular, countries with worse health infrastructure may choose to shut down quicker for fear of inability to cope with the impact of the virus. This has, in fact, been the case in many developing countries like India and South Africa. Empirically, however, we find that female-led countries with relatively good health care systems like Germany and Taiwan have led the decision to lockdown. After controlling for this, we find that female-led countries have significantly fewer deaths and also spread of COVID-19 than countries led by men.

There has been some concern that countries that are open to international travel are likely to be more badly affected by the virus, especially in the weeks before countries started closing borders. Our results show that, after controlling for such openness to travel, though female-led countries continue to have an advantage in COVID-19 deaths, they do not experience significantly lower cases. This is interesting as it confirms that women-led countries faced similar numbers of cases as other countries but they experienced fewer deaths. This seems to point to better policies and compliance in these countries.

When we match also by a gender equality measure (GII) (to consider the fact that countries that elect women are generally more equal and therefore likely to have better resilience), we find that, even after matching for gender-equitability indicators, female leadership provides an advantage.

We carry out one further test to check the robustness of our results. We drop the nations that have been in the COVID-spotlight - USA, Germany, and New Zealand - from our sample to see if they might be driving the results and we note that these changes in the sample only strengthen the results (Table 4). Finally, it is worth noting that Taiwan (a female-led country) has had a very good response to the crisis. However, we have been unable to include it because the World Bank no longer provides data for it separately from China. Given its exceptional performance during the COVID crisis, its inclusion in our data would reinforce our results rather than dampen them. 
Table 3b: Comparing COVID-outcomes in female-led countries with the nearest neighbour (extended matching)

\begin{tabular}{lccc}
\hline Dependent variable & Health expenditure & Openness to tourism & Gender equality \\
\hline COVID-cases & $-22,001.621^{* *}$ & $-16,164.047^{*}$ & $-24,639.020^{*}(N=141)$ \\
$(N=190$, unless other stated $)$ & $(10,090.670)$ & $(9,372.922)$ & $(13,605.172)$ \\
COVID-deaths & $-1,899.090^{* *}$ & $-1,344.479 * *$ & $-1,978.809 * *(N=153)$ \\
$(N=167$, unless other stated) & $(793.446)$ & $(654.175)$ & $(920.060)$ \\
\hline
\end{tabular}

Note. Standard errors in parenthesis. Results for up to five nearest neighbours are similar.

$* * \mathrm{p}<0.05, * \mathrm{p}<0.1$.

Table 4. Comparing COVID-outcomes in female-led countries without nations in the spotlight

\begin{tabular}{lccc}
\hline Dependent variable & Without the USA & Without Germany & Without New Zealand \\
\hline COVID-cases $(N=190)$ & $-20,578.153^{* *}$ & $-20,578.153^{* *}$ & $-20,578.153^{* *}$ \\
& $(9,546.513)$ & $(9,546.513)$ & $(9,546.513)$ \\
COVID-deaths $(N=167)$ & $-1,673.826^{* *}$ & $-1,673.826^{* *}$ & $-1,673.826^{* *}$ \\
& $(739.533)$ & $(739.533)$ & $(739.533)$ \\
\hline
\end{tabular}

Note. Standard errors in parenthesis.

$* * \mathrm{p}<0.05$.

\section{Policy responses to COVID-19 by gender of leader}

Our results so far confirm that women-led countries performed better in terms of the number of COVID-deaths experienced and also (though less significantly) in the number of cases. We now turn to consider whether these differences are caused by the immediate policy responses of the leaders. In particular, we are interested in whether female leaders locked down countries systematically more quickly than male leaders. The rate of transmission and deaths are likely to have been lower in countries which locked down early. Testing is another strategy that is likely to have helped with 'track and trace' type of strategies used to contain the pandemic. Given the global shortage of testing kit and associated equipment, we decided not to analyse the testing strategies of leaders. However, raw statistics indicate that the total number of tests is slightly higher in countries led by women and tests per million are significantly higher in countries led by women.

\section{- Policy responses (first step matching)}

We turn now to consider whether countries led by women locked down systematically more quickly than those led by men. The total deaths at lockdown in female-led countries are 22 fewer than male-led countries. Our matching estimates presented in Table 5a indicate that whether compared with the closest neighbours, two, three or five closest neighbours, womenled countries did close down significantly more quickly than countries led by men when considering number of deaths at lockdown. 
Table 5a. Comparing timing of lockdown in female-led countries with nearest neighbours (first step matching)

\begin{tabular}{lccc}
\hline Dependent variable $(N=128)$ & Nearest neighbour & Two Nearest & Three Nearest \\
\hline COVID-cases at lockdown & -339.320 & -176.574 & -219.622 \\
& $(340.825)$ & $(464.340)$ & $(526.868)$ \\
COVID-deaths at lockdown & $-25.203^{* * *}$ & $-25.234 * * *$ & $-24.448^{* * *}$ \\
& $(8.446)$ & $(8.424)$ & $(8.128)$ \\
\hline
\end{tabular}

Note. Standard errors in parenthesis. Results for five nearest neighbours are similar. $* * * \mathrm{p}<0.01$.

\section{- Policy response (extended matching)}

Extending our lockdown model to match for annual health expenditure, openness to tourists and GII, we find that the women-led countries locked down earlier (at lower number of deaths) than countries led by men (Table 5b). This means women leaders reacted more quickly and decisively to the crisis. Better initial outcomes in female led countries when compared to male led ones was because of this difference in responses. However, our results also make clear that the decisive factor was the number of deaths and not the number of cases at lockdown. There is no significant difference in the number of cases at lockdown for men and women led countries.

Table 5b. Comparing timing of lockdown in female-led countries with nearest neighbours (extended matching)

\begin{tabular}{lccc}
\hline Dependent variable $(N=128)$ & Nearest neighbour & Two Nearest & Three Nearest \\
\hline COVID-cases at lockdown & -339.320 & -176.574 & -219.622 \\
& $(340.825)$ & $(464.340)$ & $(526.868)$ \\
COVID-deaths at lockdown & $-25.203^{* * *}$ & $-25.234^{* * *}$ & $-24.448^{* * *}$ \\
& $(8.446)$ & $(8.424)$ & $(8.128)$ \\
\hline
\end{tabular}

Note. Standard errors in parenthesis. Results for five nearest neighbours are similar. $* * * \mathrm{p}<0.01$.

Why did women leaders respond differently to the COVID-crisis from male leaders? What might explain the difference in the behaviour of women leaders as compared to their male counterparts? In the next section, we will consider some ideas from behavioural economics and leadership literature to speculate on the sources of these differences, as well as on their implications.

\section{Discussion}

Our results above clearly indicate that women leaders reacted more quickly and decisively in the face of potential fatalities. In almost all cases, they locked down earlier than male leaders in similar circumstances. While this may have longer-term economic implications, which we cannot test here, it has certainly helped these countries to save lives, as evidenced by the significantly lower numbers of deaths in these countries. Why have women been quicker to lockdown? As discussed earlier, one idea that might have a bearing on our result is that there 
are gender-differences in attitudes to risk and uncertainty (e.g., Croson and Gneezy, 2009; Charness and Gneezy, 2012). However, this basic hypothesis has to be nuanced to highlight that women were less willing to take risks with lives but were more willing to accept risks in relation to the early lockdown of economies. We also consider learnings from the leadership literature to understand differences in leadership behaviours evidenced by men and women.

Gender differences in attitudes to risk

While risk aversion may explain why women leaders chose to close down their countries significantly early (in terms of the COVID-deaths at lockdown) when compared to their male counterparts, it does not explain the significant risk that women leaders were prepared to take with their economies by locking down early. Clearly, we need to look beyond the simplistic headline result. It could be that risks manifest differently in different domains - human life vs economic outcomes. If this were true, then women leaders could be seen as being significantly more risk averse than male leaders in the domain of human life, though, in the domain of the economy, these women leaders were clearly prepared to take more risk than male leaders.

We find some support for this idea in studies that examine risk taking behavior when lotteries are framed as losses. For example, Schubert et al. (1999) find that men are more risk averse than women when lotteries are framed as financial losses rather than gains. A similar result is also reported by Moore and Eckel (2006) who find that in the loss-domain gambles, men are more risk-averse and less ambiguity-seeking than women. It could well be that the relatively late lockdown decisions by male leaders may reflect male risk aversion to anticipated losses from locking down the economy.

Another strand of the risk literature that is of interest to us is one that considers risk-taking decisions by leaders on behalf of others in their group. Ertac and Gurdal (2012) observe that in terms of risk attitudes, the women who like to lead and decide for the group are no different from women who do not wish to lead. For men, however, they find that the ones who would like to lead tend to take more risk on behalf of the group. Similarly, studies examining confidence and associated behaviour among men and women find that while both men and women are often overconfident, men are more overconfident of success in uncertain situations than women (Barber and Odean, 2001; Niederle and Vesterlund, 2007). 
Evidence in psychology also indicates that men and women react very differently to negative experiences. Women are seen to respond more strongly and intensely than men when anticipating negative outcomes (see Fujita et al., 1991; Kring and Gordon, 1998). This can affect their utility of a risky choice and hence their decision. For example, if a negative outcome is anticipated as being worse by women than by men, they will be more risk averse when facing a risky situation, like the current pandemic. Men are also found to respond with anger to negative experiences and anger is seen to make them less cautious about future gambles, but women respond with caution, making them more prudent in their beliefs and restrained in their actions (Lerner et al. 2003).

The neuroscience literature, in its turn, indicates that there could be sex differences in feelings of empathy which cannot be fully explained as cultural derivatives of socialisation alone but have deeper neurobiological drivers. Examining the neurobiological underpinnings of male and female feelings of empathy, Christov-Moore et. al., (2014) find that there are important quantitative gender differences in the basic networks involved in affective and cognitive forms of empathy, as well as a qualitative divergence between the sexes in how emotional information is integrated to support decision making processes (see also Eckel and Grossman, 2002). When combined with the findings from the risk literature and psychology, we begin to see how women leaders could have been risk-averse about anticipated losses to human life, while at the same time taking risk with negative financial outcomes associated with early lockdown.

\section{Gender difference in leadership styles}

It is likely that leadership characteristics other than risk attitudes may also systematically differ between men and women. The early literature on leadership associated leaders with attributes that are characteristic of the stereotypic male. For example, Rost (1991) examines 221 definitions of leadership from the last century and concludes that leadership has most frequently been described as "rational, management-oriented, male, technocratic, quantitative, cost-driven, hierarchical, short-term, pragmatic and materialistic”. Of course, women can display these supposedly 'male' management traits and vice versa. For example, both Ardern and Trudeau present themselves as being socially and environmentally aware and as being able to communicate sensitively with minority groups (Lewis, 2020). Despite this, is it possible that male and female leaders are inherently different? Do male and female leadership styles differ? 
Eagly and Johnson (1990) conduct a meta-analysis of research that compares male and female leadership styles and conclude that evidence can be found for both the presence and absence of differences between the sexes. While research in organisational studies found little difference between male and female leadership styles, laboratory experiments and assessment studies found evidence to suggest that leadership styles were somewhat gender stereotypic with men likely to lead in a 'task-oriented' style and women in an 'interpersonally-oriented' manner. Consistent with this finding, women tended to adopt a more democratic and participative style and a less autocratic or directive style than men. These attributes have been seen as key in a number of studies, especially in managing a crisis (Marcus, Dorn and Henderson 2006; Waugh and Streib 2006; Van Wart and Kapucu 2011). In line with this, Zheng, Kark and Meister (2018) propose that effective women leaders may adopt a paradoxical mindset that simultaneously embrace the dual demands of their role as leaders and their gender identify to build a more resilient leadership style.

Indeed, the decisive and clear communication styles adopted by several female leaders have received much praise in the ongoing crisis (e.g., Henley and Roy, 2020; McLean, 2020; Taub, 2020). Thus, Norway's Prime Minister, Solberg, spoke direct to children answering their questions, while the New Zealand Prime Minster, Ardern, was praised for the way in which she communicated and for checking in with her citizens through Facebook Live. Evidence also suggests that good communications skills are important for women to be chosen as leaders (Lemoine, Aggarwal, Steed, 2016).

There seems to be some evidence therefore that being risk averse with respect to loss of lives and having a clear, empathetic and decisive communication style made a significant difference to immediate outcomes of the COVID pandemic in women-led countries.

\section{Conclusion}

In this paper, we ask if there is a significant and systematic difference by gender of the national leader in the number of COVID-cases and deaths in the first quarter of the pandemic. We also examine differences in policy responses by male vs. female leaders as plausible explanations for the differences in outcomes. We use a specifically constructed dataset for 194 countries for our analysis. Our findings show that COVID-outcomes are systematically and significantly better in countries led by women and, to some extent, this may be explained by the proactive 
policy responses they adopted. Even accounting for institutional context and other controls, being female-led has provided countries with an advantage in the current crisis.

Examining what is already known about the gender differences in behaviour from a variety of disciplines gives us some insights into observed differential behaviour of female and male leaders in tackling the current pandemic. The factors affecting the pandemic outcomes in various countries are likely to be complex. However, the gender of leadership could well have been key in the current context where attitudes to risk and empathy mattered as did clear and decisive communications. It is clear that many of these factors will need to be considered in the months and years ahead as the outcomes of the pandemic mature and the impacts on the economy become apparent across countries. Our analysis relates to the immediate responses of world leaders, wherein women leaders seem to have emerged highly successful.

\section{References}

Barber, Brad and Terrance Odean. 2001. Boys will be boys: Gender, overconfidence, and common stock investment”, The Quarterly Journal of Economics. 116(1): 261-92

Barnett-Howell, Zachary and Mobarak Ahmed Mush $\square$ q. 2020. The Benefits and Costs of Social Distancing in Rich and Poor Countries, arXiv:2004.04867v1 [econ.GN] https://arxiv.org/abs/2004.04867 (accessed on $20 / 05 / 2020$ )

Besley, Timothy, Jose G Montalvo and Marta Reynal-Querol. 2011. “Do Educated Leaders Matter?”, The Economic Journal, 121 (554): 205-227.

Champoux-Paillé Louise and Anne-Marie Croteau. 2020. "Why women leaders are excelling during the coronavirus pandemic", Conversation. https://theconversation.com/why-women-leaders-areexcelling-during-the-coronavirus-pandemic-138098 (accessed 20/05/2020)

Charness, Gary, and Uri Gneezy, 2012. Strong Evidence for Gender Differences in Risk Taking, Journal of Economic Behavior \& Organization,ISSN 0167-2681, http://dx.doi.org/10.1016/j.jebo.2011.06.007. Volume 83 (1): 50-58.

Christov-Moore, Leonardo, Elizabeth A. Simpson, Gino Coudéb, Kristina Grigaityte, Marco Iacobonia, Pier Francesco Ferrari.2014. Empathy: Gender effects in brain and behaviour, Neuroscience and Biobehavioral Reviews 46: 604-627.

Croson, Rachel, \& Uri Gneezy. 2009. Gender differences in preferences. Journal of Economic Literature, 448-474.

Durrant, Gabriele B. 2009. Imputation methods for handling item-nonresponse in practice: methodological issues and recent debates, International Journal of Social Research Methodology, 12:4, 293-304.

Eagly, Alice H. and Blair T Johnson. "Gender and Leadership Style: A Meta-Analysis" 1990.

CHIP Documents. 11. https://opencommons.uconn.edu/chip_docs/11 (accessed 02/05/2020)

Eckel, C., Grossman, P., 2002. "Sex differences and statistical stereotyping in attitudes toward financial risk", Evolution and Human Behavior, 23, 281-295.

Ertac Seda, Mehmet Y. Gurdal. 2012. “Deciding to decide: Gender, leadership and risk-taking in groups”, Journal of Economic Behavior \& Organization, 83:24-30.

Finucane, Melissa L., Paul Slovic, C. K. Mertz, James Flynn, and Theresa A. Satterfield. 2000. “Gender, Race, and Perceived Risk: The 'White Male' Effect.” Health, Risk and Society, 2(2): 159-72.

Fujita, Frank, Ed Diener, and Ed Sandvik. 1991. "Gender Differences in Negative Affect and Well-Being: The Case for Emotional Intensity.” Journal of Personality and Social Psychology, 61(3): 427-34.

Gallagher, James.2020. https://www.bbc.co.uk/news/health-51963486(accessed 20/05/2020)

Gemmill, Gary and Judith Oakley. 1992. “Leadership: An Alienating Social Myth?” Human Relations, XLV, 113-129. 
Goodall, Amanda H, Lawrence M. Kahn and Andrew J. Oswald. 2011. "Why do leaders matter? A study of expert knowledge in a superstar setting.” Journal of Economic Behavior \& Organization, 77(3): 265-284.

Henley, Jon and Eleanor Ainge Roy. 2020. Are female leaders more successful at managing the coronavirus crisis?, Guardian, 25 $5^{\text {th }}$ April https://www.theguardian.com/world/2020/apr/25/why-do-female-leadersseem-to-be-more-successful-at-managing-the-coronavirus-crisis (accessed 25/05/2020)

Jones, Benjamin and Benjamin A. Olken. 2005. "Do Leaders Matter? National Leadership and Growth Since World War II” The Quarterly Journal of Economics, 120(3): 835-864.

Keegan, John. 2003. "Winston Churchill," Time Magazine, World Wide Web: http:// www.time.com/time/time100/leaders/prole/churchill.html. (accessed 10/05/2020)

Kring, Ann M and Albert H. Gordon.1998. "Sex Differences in Emotion: Expression, Experience, and Physiology,” Journal of Personality and Social Psychology, 74(3): 686-703

Lerner, Jennifer S., Roxana M. Gonzalez, Deborah A. Small, and Baruch Fischhoff. 2003. "Effects of Fear and Anger on Perceived Risks of Terrorism: A National Field Experiment.” Psychological Science, 14(2): 14450.

Lemoine G. James, Aggarwal Ishani, Laurens Bujold Steed. 2016. "When women emerge as leaders: Effects of extraversion and gender composition in groups”, The Leadership Quarterly, 27(3): 470-486.

Lewis Helen. 2020. The Pandemic has Revealed the Weakness of Strongmen, The Atlantic, $6^{\text {th }}$ May. https://www.theatlantic.com/international/archive/2020/05/new-zealand-germany-women-leadershipstrongmen-coronavirus/611161/ (accessed 20/05/2020)

Marcus, Leonard J., Barry C Dorn and Joseph M. Henderson. 2006. Meta-Leadership and National Emergency Preparedness: A Model to Build Government, Biosecurity and Bioterrorism, 4(2): 128-134.

McLean, V. 2020. Coronavirus is showing yet again why the world needs more strong female decision-makers, $12^{\text {th }}$ April, https://www.euronews.com/2020/05/12/coronavirus-showing-yet-again-why-the-world-needsmore-strong-female-decision-makers-view (accessed 20/05/2020)

Moore Evan and Catherine Eckel. 2006. “Measuring ambiguity aversion”, Research Gate. https://www.researchgate.net/publication/228790553_Measuring_ambiguity_aversion_ (accessed 05/05/2020)

Nelson A Julie. 2015. “Are women really more risk-averse than men? A re-analysis of the literature using expanded methods”, Journal of Economic Surveys, 29(3): 566-85.

Niederle, Muriele and Lise Vesterlund.2007. Do women shy away from competition? Do men compete too much? The Quarterly Journal of Economics, 122(3):1067-1101

Nikolich-Zugich, Janko., Kenneth S Knox, Carlos Tafich Rios, Natt Bhupinder, Deepta Bhattacharya and Mindy J. Fain. 2020. "SARS-CoV-2 and COVID-19 in older adults: what we may expect regarding pathogenesis, immune responses, and outcomes”, GeroScience, 42:505-514.

Rost, Joseph C.1991. Leadership in the 21st Century. New York: Praeger

Schubert, Renate, Martin Brown, Matthias Gysler, and Hans Wolfgang Brachinger. 1999. "Financial DecisionMaking: Are Women Really More Risk-Averse?” American Economic Review, 89(2): 381-85.

Stuart Elizabeth A. , 2010. Matching Methods for Causal Inference: A Review and a Look Forward, Statistical Science, 25, (1):1-21.

Taub Amanda. 2020. “Why Are Women-Led Nations Doing Better With Covid-19?”, New York Times, 15 May. https://www.nytimes.com/2020/05/15/world/coronavirus-women-leaders.html (accessed 25/05/2020)

Van Wart, Montgomery and Naim Kapucu. 2011. "Crisis Management Competencies: The case of emergency managers in the USA”, Public Management Review, 13 (4): 489-511.

Waugh, William L. and Gregory Streib. 2006. Collaboration and Leadership for Effective Emergency Management, Public Administration Review, 66(1): 131-140.

Wittenberg-Cox, Avivah. 2020. "What do countries with best coronavirus responses have in common?”, Forbes. 13/04/2020. https://www.forbes.com/sites/avivahwittenbergcox/2020/04/13/what-do-countries-with-thebest-coronavirus-reponses-have-in-common-women-leaders/\#3ce529813dec (accessed on 10/05/2020)

Zhang, Juanjuan, Maria Litvinova, Yuxia Liang, , Yan Wang, Wei Wang, Shanlu Zhao, Qianhui Wu, Stefano Merler, Cécile Viboud, Alessandro Vespignani, Marco Ajelli, Hongjie, Yu. 2020. "Changes in contact patterns shape the dynamics of the COVID-19 outbreak in China”, Science, 29 April.

Zheng Wei., RonitKark, Alyson L.Meister. 2018. "Paradox versus dilemma mindset: A theory of how women leaders navigate the tensions between agency and communion”, The Leadership Quarterly, 29(5): 584-596 